DOI 10.26726/2305-4484-2017-3-27-35

УДК 338. КАЗИХАНОВ АДИЛЬХАН МАГОМЕД-ТАГИРОВИЧ

д.э.н., профессор кафедры «Политическая экономия» ФГБОУ ВО "Дагестанский государственный университет", e-mail:cool.kazikhanov@mail.ru

КУРБАНОВ ГАДЖИ КУРБАНОВИЧ

преподаватель кафедры «Политическая экономия» ФГБОУ ВО "Дагестанский государственный университет", e-mail: kurbanov_gadzhe@mail.ru

\title{
КААСТЕРЫ КАК ТОЧКИ РОСТА ЭКОНОМИКИ В АПК РЕГИОНА
}

Аннотауия. Предмет и уель работы. Предмет исследования - обоснование необходимости более эффективного использования природно климатических факторов региона на

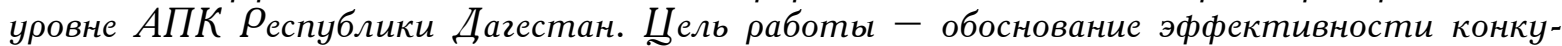
рентных преимуществ кластерной структуры АПК региона. Поставленная иель обуславливает необходимость решения ряда задач. Методология проведения работы. Обозначена актуальность повышения конкурентоспособности и эффективности АПК, его

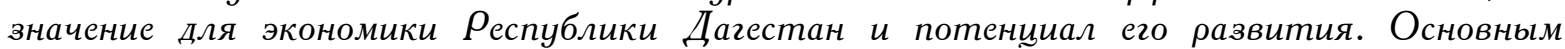
фактором способствующим повышению конкурентоспособности АПК авторы видят в применении кластерного подхода. Проведен анализ конкурентных преимуществ кластерной структуры виноградно-винодельческого подкомплекса АПК состояния и перспектив развития АПК. Проведен анализ АПК на примере виноградно-винодельческого подкомплекса, как наиболее типичного и одного из приоритетного направления развития экономики республики. Обоснована необходимость решения следующих первоочередных проблем, рассчитанных на долгосрочный период: проблема сортамента виноградников, гос. Управления и собственности. Проведен SWOT - анализ. Показано, что стратегическим направлением развития отрасли, является выход на мировой рынок. Предложен один из вариантов кластера - коньячный кластер, который обеспечит выход отрасли на внешний рынок. Результаты работы. На основе проведенного исследования виноградно

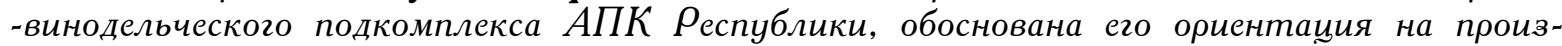
водство продукиии для экспорта преимущественно в форме коньячной продукиии. Показано преимущество экспортоориентированного развития отрасли, обеспечивающей

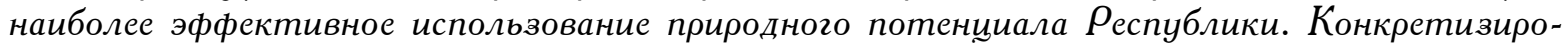
ваны первоочередные проблемы, требующие своего решения. Показана необходимость внесения корректив в действующую программу развития подкомплекса. Предложена модель коньячного кластера и даны основные этапы его формирования. Область применения результатов. Полученные результаты могут быть использованы при разработке экспортоориентированной программы развития подкомплекса. Их использование обеспечит уход о сырьевой ориентации производства продукиии в подкомплексе. Выводы. $B$ основе новой модели экономики лежат: повышение эффективности управления, переход на экономику знаний и рост производительности труда. При этом оост экспорта готовой продукции является определяющим фактором перехода на новую модель экономики. В данной статье рассмотрены проблемы развития АПК и повышения конкурентоспособности. Обозначена актуальность повышения конкурентоспособности и эффективности АПК, его значение для экономики республики Дагестан и потенииал развития. Основным, фактором способствующим повышению конкурентоспособности АПК авторы наряду с внедрением инноваций и обновлением технического парка, видят применение кластерного подхода. Проведен анализ конкурентных преимуществ кластерной структуры винаградно-винодельческого подкомплекса AПК и SWOT-анализ состояния и перспектив развития АПК. Предложена модель коньячного кластера.

Ключевые слова: кластер, кластерный механизм, конкурентоспособность, кластерная модель, винаградно-винодельческий подкомплекс. 
KAZIKHANOV ADILKHAN MAGOMED-TAGIROVICH

Doctor of Economics, Professor of the Department of "Economic Theory" of SAEI of HE

"Dagestan State Institute of the Economy", e-mail:cool.kazikhanov@mail.ru

KURBANOV GADJI KURBANOVICH

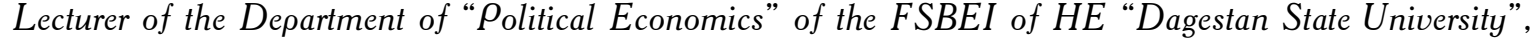
e-mail: kurbanov_gadzhe@mail.ru

\section{CLUSTERS AS POINTS OF ECONOMIC GROWTH IN THE AIC OF THE REGION}

Abstract. The subject and goal of the study. The subject of the study is substantiation of a need for a more effective use of the natural climatic factors of the region at the level of the AIC of the Republic of Dagestan. The goal of the study is substantiation of the effectiveness of competitive advantages of the cluster structure of the AIC of the region. The goal set substantiates the need to solve a set of tasks. The methodology of performing the work. We have specified the relevance of improving the competitive ability and effectiveness of the AIC, its importance for the economics of the Republic of Dagestan, and the potential of its development. The authors see the main factor that promotes the improvement of the competitive ability of the AIC in the use of the cluster approach. We have analyzed the competitive advantages of the cluster structure of the vinicultural-winemaking sub-complex of the AIC state and prospects of development of the AIC. We have analyzed the AIC on the example of the vinicultural-winemaking sub-complex as the most typical and one of the priority areas of focus of development of the economics of the republic. We have substantiated the need to solve the following paramount problems developed specifically for the long-term period: the problem of the assortments of vineyards, state management and private property. We have performed a SWOT analysis. We have shown that entering the international market is a strategic area of focus of development of the industry. We have suggested one of the options of a cluster - a cognac cluster which will ensure that the industry obtains access to the overseas market. The results of the study. Based on the study performed of the vinicultural-winemaking sub-complex of the AIC of the Republic, we have substantiated its orientation on the manufacturing of products for export mostly in the form of cognac products. We have shown the advantage of the export-oriented development of the industry that ensures having the most effective use of the natural potential of the Republic. We have specified the top priority problems that require to be resolved. We have shown the need to make changes in the present program of development of the sub-complex. We have suggested a model of the cognac cluster and we have given the main stages of forming it. The area of application of the results. The results that we have achieved may be used when developing an export-oriented program of development of the sub-complex. Their use will ensure moving away from the raw material orientation of manufacturing products in the sub-complex. Conclusions. The basis of the new model of the economy is the following: improving the effectiveness of management, transition towards the economics of knowledge and growth of labor productivity. At the same time, the growth of export of finished products is the determining factor of transitioning towards a new model of economics.

Keywords: a cluster, a cluster mechanism, competitive ability, a cluster model, a viniculturalwinemaking sub-complex.

\section{Введение}

Переход на новые технологии и инновации сегодня связаны в первую очередь с ростом влияния глобализации. В этих условиях переход на новую цифровую экономику можно рассматривать как очередную революцию в развитии экономики. Именно повышение эффективности государственного управления, конкурентоспособности, качества, переход на экономику знаний, повышение производительности труда и уровня жизни населения лежит в основе новые модели экономики. Изменится сам рынок, то есть товары будут производиться под кон- 
кретного покупателя, а это уже новое содержание закона спроса и предложения. Однако в настоящее время многие проблемы новой модели экономики пока остаются нерешенными, нет и механизма их решения, а также правовых, технических, организационных и финансовых условий для его развития. В условиях интеграции России в мировую экономику переход на новую модель выходит на первый план. Это является и одним из основных факторов снижения кризисных явлений внутри страны. Очевидно, что новая модель в таком его понимании является на современном этапе стратегическим направлением развития общественного производства, обеспечивающее социальную стабильность в стране. На данном этапе экономика России продолжает оставаться сырьевым придатком мировой экономики. Так же очевидно и то, что место России в экономике будет зависеть от динамики роста экспорта готовой продукции в структуре внешнеэкономических отношений. Сценарий долгосрочного развития экономики России предполагает переход на новую экономику, которая потребует создания системы четкого взаимодействия государства, бизнеса и образования, среди которых свою позитивную роль должен сыграть кластерный подход и политика. Кластерная политика является, на наш взгляд, комплексом мероприятий, который будет способствовать решению главной задачи переходу на новую модель экономики.

Актуальность темы обусловлена наличием природных и экономических факторов в регионе и необходимость их эффективного использования. В нашем исследовании сделана попытка решения этой проблемы на уровне АПК Республики Дагестан.

\section{Методы исследования}

Цель работы обуславливает необходимость решения ряда задач:

1. Оценка конкурентоспособности исследуемые отрасли:

2. Изучение теоретической базы «кластерной экономики»:

3. Обоснование специализации отрасли:

4. Проведение SWOT-анализа состояния отрасли.

В качестве объекта исследования выбран виноградно-винодельческий подкомплекс АПК Республики Дагестан.

Конкурентоспособность это емкое понятие. Различают конкурентоспособность товара, производителя, отрасли и др. Обобщающим показателем этого понятия можно считать региональную конкурентоспособность. Его следует рассматривать в связи с эффективностью управления на уровне региональной экономики, так как она является следствием преимуществ в деятельности субъектов экономики. При этом, очевидно, необходимо выделить отрасли, которые является базой для развития экономики региона. В теоретическом аспекте единственное, на чём может основываться концепция конкурентоспособности на уровне региона - это продуктивность использования ресурсов $[1$, с.250]. Можно констатировать, что необходимым условием повышения конкурентоспособности региона является выбор отраслей, в деятельности которых максимально эффективно используются наличные природно-климатические условия и которые могут составить в будущем ядро развития отрасли.

Под кластером понимается группа географически соседствующих компаний взаимосвязанных компаний и связанных с ними организаций, действующих в определенной сфере, характеризующейся общностью деятельности и взаимодополняющих друг друга. Кластеры могут иметь различные масштабы, сложность, глубину. Чаще всего кластеры представлены крупными компаниями производящими конечный товар, фирмами поставляющими факторы производства и комплектующие изделия, а так же финансовыми институтами и фирмами в сопутствующих отраслях. В кластеры так же входят правительственные организации, научноисследовательские институты, обучающие центры, а так же множество мелких фирм производящих побочную продукцию. Кластеры способствуют повышению конкурентоспособности входящих в нее компаний за счет следующих преимуществ:

1. Доступа к специализированным факторам производства;

2. Улучшение доступа к информации;

3. Взаимодополняемости фирмами друг друга;

4. Улучшение доступа к общественным благам.

Важной особенностью кластеров является то, что основной выигрыш конкуренции достигается не в крупных компаниях входящих в кластер и даже не в данной отрасли, а в местах 
расположения дочерних предприятий.

За последние 10 лет кластерная политика стала одним из главных направлений государственной политики на уровне макроэкономики. Вопросы стимулирования кластеризации нашли отражение и в «Концепции стратегии социально-экономического развития РФ до 2020 г.» [5]Выявлено что кластерная политика обеспечивает устойчивый рост конкурентоспособности предпринимательства за счёт использования преимуществ взаимодействия участников кластера с географически близким расположением предприятий специфических услуг и снижения трансакционных услуг. Основными результатами эффективной кластерной политики должны быть: увеличения объемов валового регионального продукта, вовлечение в кооперационные связи местных предприятий; дополнительный импульс для развития малого и среднего бизнеса, что способствует повышению занятости населения и увеличению налоговых поступлений в бюджет республики.

Республика Дагестан является одним из крупных производителей винограда и продуктов его переработки. Виноградно-винодельческий подкомплекс в Республике позволяет наиболее эффективно использовать природно-климатические условия Республики. Одной из стратегических задач стоящей перед комплексом является производство конкурентоспособной продукции и ее продвижение на мировой рынок. Для этого в Республике есть все основания. Площади виноградников в настоящее время (2015 г.) составляет 21,7 тыс. га, что составляет $36,6 \%$ от площади виноградников в России.

Применение кластерной политики и кластерных технологи к виноградарновинодельческому подкомплексу АПК считаем обоснованным, так как эффективность этого подтверждается такими известными зарубежными проектами, как винодельческие кластеры в Калифорнии(США) и Баден-Вюртемберге (Германия). Традиционно в своем развитии подкомплекс прошел периоды своего подъема и спада, обусловленные экономическим и политическим факторами.

Основными этапами развития подкомплекса, которые привели к формированию и устойчивому развитию были:

1. 1960-1966 гг., становление и развитие основной хозяйствующей структуры подкомплекса (Дагвино);

2. Организация (1968 г.) треста виноградарских совхозов;

3. Организация (1969 г.) треста плодовых и плодопитомнических совхозов.

Организация 2 трестов была связана с событием, которое произошло на всесоюзной дегустации вин и коньяков (Магарыч, Крым 1967 г.), когда коньяк кизлярского коньячного завода получил высшую оценку, опередив всемирно известный французский коньяк Наполеон. Перед отраслью была поставлена задача выйти с новой продукцией (коньяк Кизлярского завода Багратион) на внешний рынок. АПК республики получил финансовую поддержку, для активизации исследовательской работы АПК был создан НИИ пищевой промышленности. Производство винограда планировалось довести к 1980 году до 450 тыс. тонн в год. Однако после известного постановления ЦК КПСС (О борьбе с алкоголизмом) все три структуры были расформированы, а хозяйства переданы в ведение МСX Республики. В результате этого к 1990 году производство винограда в Республике упало до 35 тыс. тонн в год. [2, с.55]

Реальное возрождение АПК Республики началось с 2002 года и связано с принятием следующих нормативных актов:

1. Формируются приоритетные проекты по основным отраслям экономики республики, в том числе и по АПК.

2. Принимается программа «Развитие виноградарства и виноделия Республики Дагестан на 2011-2020 годы».

3. Принимается государственная программа «Развитие сельского хозяйства и регулирование рынков сельскохозяйственной продукции, сырья и продовольствия на 2014-2020 годы».

В результате реализации этих программ валовой сбор винограда в Республике в 2016 году составил 150 тыс. тонн. Кроме того:

1. Достигнута договоренность о том, что динамика развития отрасли с 2017 года будет контролироваться на федеральном уровне с последующей финансовой поддержкой;

2. МСХ РД объявил конкурс на создание питомниководческого комплекса в РД стоимо- 
стью 500 миллионов руб.

В результате реализации приведённых нормативных актов и приоритетных проектов созданы благоприятные условия для обеспечения устойчивого развития отрасли и, наконец, возможности выхода продукции исследуемого подкомплекса на международный уровень, который на данном этапе его развития является единственным эффективным направлением его стратегического развития. Первоочередными проблемами требующими своего решения являются:

Проблема №1. Увеличение общей площади виноградников должно сопровождаться изменением сортамента виноградников в сторону увеличения площадей под коньячными сортами. Необходимо ориентировать работу НИИ пищевой промышленности на проведение исследований именно в этом направлении. Конечная цель - это переход на производство готовой коньячной продукции и производство полуфабрикатов, каким является производство виноматериалов, реализация которых в РД со временем будет падать, так как на это большое влияние оказывает и религиозный фактор.

Необходима ориентация на внешний рынок, где коньячная продукция является наиболее востребованной, а для АПК и экономически эффективной. [9, с.85]

Параллельно с этим необходимо модернизация технической базы перерабатывающей промышленности. АПК в рамках импортозамещения на базе машиностроительной промышленности Республики. Известно, что износ оборудования перерабатывающей промышленности АПК Республики превышает 90\%.[3, с.300]

Проблема №2. Государственное управление - решающий фактор повышения эффективности функционирования АПК. Такой подход должен быть положен в основу решения проблемы. Известно, что сегодня существует и другой подход путем приватизации как один из направления рыночных реформ. При этом делается ссылка на зарубежный опыт. Но есть страны, где влияние государства на АПК значительно. Например, в Израиле почти вся земля 99\% находится в государственной собственности и передается в аренду на 49 лет. При этом сельское хозяйство функционирует как единый кластер, который находится под постоянным контролем и опекой правительственных организаций. В настоящее время сельское хозяйство Израиля считается наиболее развитой и его инновационные методы и технологии в сфере АПК используют многие страны, в том числе США и Япония. [15, с.50]

Таким образом, государственное управление следует рассматривать как важнейший фактор стратегического развития подкомплекса. Анализ и изучение роли государства в странах с развитым АПК проведенный ВНИЭТУСХ свидетельствует об обоснованности усиления роли государства и государственного регулирования в АПК.

Проблема №3. Это проблема собственности. В целом за последние 25 лет заметных позитивных сдвигов в аграрном секторе не произошло, в то время как частная собственность стала преобладающей. Более того, возникла новая проблема - проблема продовольственной безопасности. Реальная ситуация в аграрном секторе характеризуется отсутствием хорошей техники, дорогими кредитами, налоговым давлением и многим другим. Все это говорит о том, что введение частной собственности на земли сельскохозяйственного назначения это еще не аграрная реформа, а только ее часть, причём не самая эффективная. Изучение природы такого положения дела говорит лишь об одном - это результат низкого уровня государственного управления. И это еще раз подтверждает неэффективность частной собственности на земли сельскохозяйственного назначения.

С учетом вышеизложенного, на наш взгляд необходимо:

1. Внести коррективы в программу «Развития виноградарства и виноделия в РД на 20112020 гг.» по изменению сортамента виноградников в процессе его закладки в сторону увеличения площадей под коньячными сортами и провести модернизацию перерабатывающей промышленности АПК;

2. Усилить роль государственного управления как решающего фактора развития АПК;

3. Сохранить за государством собственность на земли сельскохозяйственного назначения.

Для обоснования перспективных направлений развития отрасли и формирования кластеров нами проведен SWOT-анализ. Результат проведенного анализа по исследуемому подкомплексу приведён на рис. 1. 
КАЗИХАНОВ А.М., КУРБАНОВ Г.К.

КЛАСТЕРЫ КАК ТОЧКИ РОСТА ЭКОНОМИКИ В АПК РЕГИОНА

\begin{tabular}{|l|l|}
\hline \multicolumn{1}{|c|}{ Сильные стороны } & \multicolumn{1}{|c|}{ Слабые стороны } \\
\hline $\begin{array}{l}\text { - Благоприятные природно-климатические условия } \\
\text { - Кадровые ресурсы } \\
\text {-Наличие приоритетного проекта } \\
\text { - Активный предпринимательский потенциал }\end{array}$ & $\begin{array}{l}\text { - Устаревшее оборудование и технологии } \\
\text { - Слабая защищенность от подделок } \\
\text { - Влияние религиозного фактора } \\
\text { Угрозы }\end{array}$ \\
\hline \multicolumn{1}{|c|}{ - Неразвитость питомникового хозяйства } \\
\hline $\begin{array}{l}\text { - Активное развитие стран-конкурентов } \\
\text { - Нелегальный импорт }\end{array}$ & \multicolumn{1}{|c|}{ Возможности } \\
\hline
\end{tabular}

Pис. 1. SWOT-анализ отрасли.

Далее формируется «Матрица возможностей» представленная на рис. 2, по которой можно выявить прогнозные направления развития отрасли, которые находятся на пересечении сильных и слабых сторон отрасли, а также возможностей и угроз. Из рис. 2 видно, что стратегическим направлением развития отрасли является выход на мировой рынок внедрение новых сортов винограда, приток инвестиций.

\begin{tabular}{|c|c|c|c|c|c|}
\hline & \multicolumn{2}{|c|}{ Сильные стороны } & \multicolumn{2}{|c|}{ Слабые стороны } \\
\hline & & \multirow[t]{2}{*}{$\begin{array}{c}\text { Предпринимательский } \\
\text { потенциал }\end{array}$} & \multirow[t]{2}{*}{$\begin{array}{c}\text { Благоприятные } \\
\text { природные } \\
\text { условия }\end{array}$} & & $\begin{array}{c}\text { Низкое качество } \\
\text { продукции }\end{array}$ \\
\hline \multirow{2}{*}{ Угрозы } & $\begin{array}{c}\text { Рост притока } \\
\text { напитков }\end{array}$ & & & $\begin{array}{c}\text { Снижение объемов } \\
\text { производства вино- } \\
\text { материалов }\end{array}$ & $\begin{array}{c}\text { Снижение } \\
\text { спроса на } \\
\text { продукцию }\end{array}$ \\
\hline & $\begin{array}{c}\text { Активное } \\
\text { развитие } \\
\text { конкурентов }\end{array}$ & $\begin{array}{c}\text { Приход конкурентов на } \\
\text { внутренний рынок }\end{array}$ & & $\begin{array}{l}\text { Рост себестоимо- } \\
\text { сти продукции }\end{array}$ & $\begin{array}{c}\text { Потеря доли } \\
\text { внутреннего } \\
\text { рынка }\end{array}$ \\
\hline \multirow{2}{*}{$\begin{array}{c}\text { Возмож- } \\
\text { ности }\end{array}$} & $\begin{array}{c}\text { Рост роли } \\
\text { маркетинга }\end{array}$ & \multirow{2}{*}{$\begin{array}{c}\text { Улучшение качества } \\
\text { продукции }\end{array}$} & $\begin{array}{c}\text { Приток } \\
\text { инвестиций }\end{array}$ & & $\begin{array}{c}\text { Реклама } \\
\text { продукции }\end{array}$ \\
\hline & $\begin{array}{c}\text { Освоение } \\
\text { новых } \\
\text { технологий }\end{array}$ & & $\begin{array}{c}\text { Выход на } \\
\text { мировой рынок }\end{array}$ & & $\begin{array}{c}\text { Улучшение } \\
\text { качества } \\
\text { продукции }\end{array}$ \\
\hline
\end{tabular}

Puc. 2. SWOT - матрица возможностей.

Из рис. 2 видно, что стратегическим направлением развития отрасли является выход на мировой рынок, внедрение новых сортов винограда, приток инвестиций. Из этого также следует, что кластер в исследуемой отрасли экспортоориентирован и обеспечивает более эффективную взаимосвязь предпринимательства, государства и науки.

\section{Результаты}

Создавая возможности производить конкурентоспособную продукцию кластеры открывают перспективы для выхода на внешний рынок. Наибольшую заинтересованность в создании кластеров проявляет предпринимательство. Поэтому на начальном этапе им необходима поддержка и создание благоприятного бизнес-климата, что очень важно и для привлечения иностранных инвестиций. Формирование коньячного кластера в Республике будет способствовать развитию одновременно и малого, и среднего предпринимательства вокруг крупных предприятий, давая им обоюдную выгоду. Крупным это приведет к снижению издержек, а для небольших это возможность инновационного развития. Изменится сама конкуренция, которая приведёт к распространению конкурентных преимуществ. Основой для создания кластеров, видимо, будут крупные предприятия, которые стабильно развиваются и уже сегодня могут составить конкуренцию иностранным производителям. Инициатива таких предприятий будет решающим фактором формирования кластера. Важным фактором является и состояние, и износ основных фондов, которые сегодня характеризуется технической и технологической отсталостью. Выход из этого положения очевиден - это поддержка и внедрение инноваций, что 
также под силу крупным предприятиям.

Предприятие нуждается и в информации. И здесь участие в кластере имеет свои преимущества, в частности, в направлении снижения трансакционных издержек, взаимодополняемости видов деятельности, реального осуществления инноваций и др. Следует отметить также, что преимуществом кластера является то, что каждый его участник получает необходимые конкретно ему преимущества, организационную гибкость и быструю приспособляемость к меняющимся внешним условиям. В условия кластеризации меняется и роль государства, затрагивающая его экономические задачи в рамках внутреннего и внешнего рынков отраслей. В конечном счёте рост конкурентоспособности региона достигается за счёт более эффективной деятельности отраслей, выходом на внешние рынки и повышения качества продукции. И здесь формирование и развитие кластеров выступает эффективным механизмом привлечения иностранных инвестиций. Подводя итог можно предложить один из вариантов коньячного кластера, который может быть сформирован в Республике Дагестан (рис. 3).

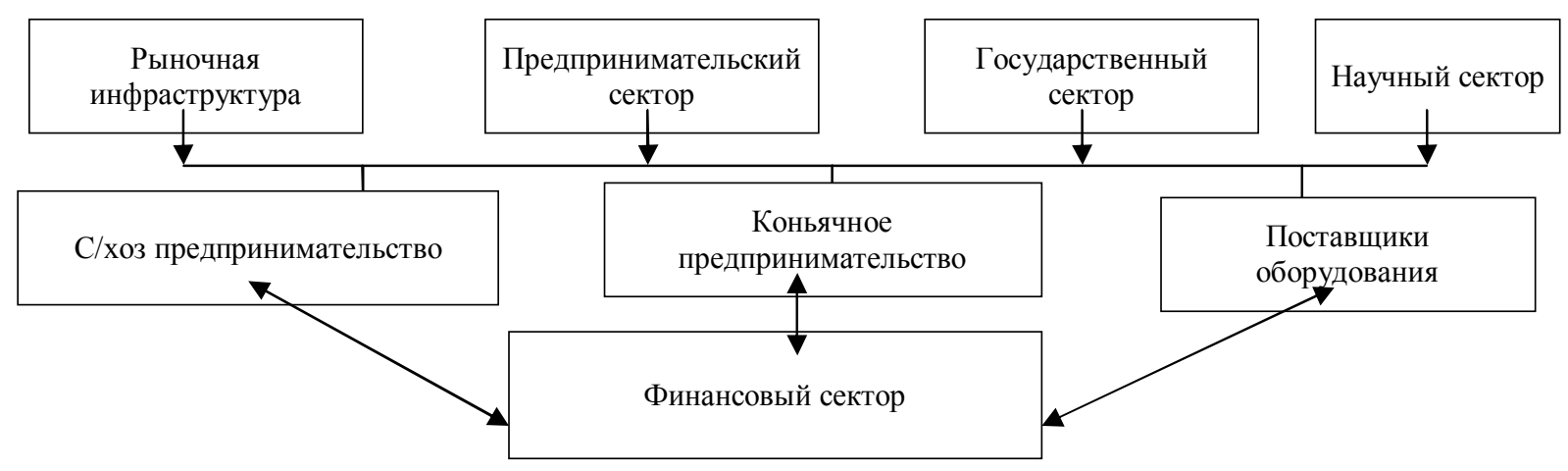

Pис. 3. Модель коньячного кластера.

Кластеры в будущем будут выполнять роль точек роста внутреннего рынка, развитию внешнеэкономических связей с соответствующими отраслями зарубежных стран, способствовать росту инновационного потенциала и укреплению статуса экспортоориентированной отрасли.

Следует подчеркнуть, что кластерный подход обогатит экономическое сотрудничество на региональном уровне и принесет результаты только тогда, когда она будет вписана в стратегию регионального развития в качестве одного из его направлений. На это указывал и теоретик кластерного подхода [1]

Идея комплексного подхода в отношении регионального экономического развития показала свою эффективность. Поэтому необходимо принятие нормативных актов (законов, распоряжений и т.п.) по поддержке кластеров особенно для развития предпринимательского сектора экономики.

Законодательная база должна как минимум охватить три этапа формирования конкурентоспособного кластера.

I этап - анализ предпосылок создания кластера, включающий наличие природных ресурсов и участников.

II этап - формирование структуры, разработка положений и правил взаимодействия участников кластера.

III этап - оценка эффективности кластера (социальной и экономической).

\section{Выводы:}

Переход на новую модель экономики требует глубоких изменений в экономической, социальной и культурной сферах. Основу новой модели, на базе экономики знаний, составят повышение эффективности управления, качество и производительность труда. Переход на экспорт готовой продукции обеспечит производство коньячной продукции в рамках кластерной структуры подкомплекса. Будет положено начало перехода от производства полуфабриката к производству готовой коньячной продукции и АПК республики перестанет быть сырьевым придатком мировой экономики, что будет способствовать скорейшему достижению стратегических целей экономики Республики Дагестан. 
Лuтература

1. Портер Ю.М. Международная конкурениия. М.,: Международные отномения. 1993. 896 с.

2. Пулатов 3. В. Рациональное использование земли - основа устойчивого развития сельского хозяйства

и регулирования продовольственной проблемы экономики. // Региональные проблемы преобразования экономики. ДНЦ РАН ИСЕП, 2013. №2, с. 80-85.

3. Казиханов А. М. Современные проблемы инновачий в АПК. // Фундаментальные исследования. М., № 8, c. 338 .

4. Карпова В.В., Алещенко В.В. Кластерный подход к развитию агропромышленного комплекса Омской области. - Новосибирск: издательство СО РАН 2014 2, 416 с.

5. Распоряжение Правительства РФ от 17.11.2008 № 1662-p «О концепции долгосрочного сочиильноэкономического развития РФ на период до 2020 года».

6. Тохчуков Р.Р. Предпринимательский агропромышленный кластер: теоритические основы создания и функционирования в системе АПК..// Современные научные исследования. 2012 г. с 20.

7. Горетов И. Н. Кластерные технологии в управлении АПК// - Вестник Чувашского университета. 2009 № 1 c. 380

8. Кундиус В.А. Кластерый подход в реализации стратегии инновационного развития АПК региона // Экономика региона 2011 2. №4 cmp.110

9. Стратегия инноваџионного развития РФ на период до 2020 года.// собрание законодательства РФ от 2 января 2012 г.№1 c. 210

10. Симонов Б.П. Королева Е.В. Инноваџионная экономика России: проблемы становления и развития// вестник финансового университета. М.2011 №1c. 5-10

11. Экономический словарь. Под редакичей А. И. Архипова // проспект $2010624 c$.

12. Салимова Т.А. Управление качеством: учебное пособие М; Издательство «ОМГА-Л» 2011 г. $416 \mathrm{c.}$

13. Тимошенко В. А. Проблемы формирования и развития интегрированных структур в АПК // Вестник Воронежского Государственного аграрного университета 2012 № 4 c. 110

14. Об утверждении Доктрины продовольственной безопасности РФ (Электронньий ресурс. Доступ из справочно правовой системы «Консультант+»

15. Горетов И. Н. Теоритические и практические аспекты в интеграции АПК// Актуальные проблемы гуманитарных и естественных наук. 2009 № 10 c.110

16. Хуажева А.Ш. Организационно-институциональная модель управления региональным АПК на основе выделения экономических кластеров. // Вестник Адыгейского государственного университета № 2007 2. c. 220

17. Цихан Т. В. Кластерная теория экономического развития // теория и практика управления 2003 № 5 c. 15

18. Лизунов В.В. и др. Кластеры и кластерные стратегии издатель ИП Скорнякова Е.В. 2012280 .

19. Трескова Е. А., Семин А. Н. Конщепџия развития сельских территорий: два базовых подхода. // Аграрный вестник Урала №12 2012 с. 60

20. Белая Н.В. Формирование человеческого капитала в АПК: Проблемы и перспективы. // Вестник Алтайского аграрного государственного университета. 2013 г. №6 c.113.

21. Ali Sasani. Investigating the Effect of Human Capital and Social Capital on Innovation Using the Fuzzy AHP Method // New York Science Journal. - 2012. - № 5(11).

22. Белая Н.В. Формирование человеческого капитала в АПК: Проблемы и перспективы. // Вестник Алтайского аграрного государственного университета. 2013 г. №6 c.113.

23. Ali Sasani. Investigating the Effect of Human Capital and Social Capital on Innovation Using the Fuzzy AHP Method // New York Science Journal. - 2012. - № 5(11).

\section{References:}

1. J. M. porter international competition. M.: International relations. $1993.896 p$

2. Pulatov Z. V. Rational use of land - the basis of sustainable development of agriculture and regulation of food problems of the economy. // Regional problems of transformation of the economy. DNTS RAN ISEP, 2013. No. 2, pp. 80-85.

3. Kazikhanov A. M. Modern problems of innovation in agriculture. // Fundamental research. M., no. 8, pp. 338 .

4. Karpov V. V., Aleshchenko V. V. Cluster approach to the development of agro-industrial complex of Omsk region. - Novosibirsk: publishing house so ran, 2014, $416 \mathrm{p}$.

5. The decree of the RF Government from 17.11.2008 № 1662-R About the concept of long-term socioeconomic development of the Russian Federation for the period till 2020."

6. Tokhchukova R. R. agro-industrial Business cluster: theoretical bases of creation and functioning in the agricultural sector..// Modern scientific researches. 2012 from 20.

7. Gorelov I. N. Clustering technology in the management of agricultural and industrial complex// Bulletin of the Chuvash University. 2009 No. 1, p. 380

8. Kundius $V$. A. Klastery approach in realization of strategy of innovative development of agribusiness in the region // regional Economy, 2011 No. 4 p. 110

9. The strategy of innovative development of the Russian Federation for the period till 2020.// meeting of the legislation of the Russian Federation of 2 January 2012 No. 1 s 210

10. Simonov B. P. Koroleva E. V. Innovative economy of Russia: problems of formation and development// Vestnik of financial University. 2011 M. No. 1s. 5-10

11. Dictionary. Edited by A. I. Arkhipova // prospect $2010624 c$.

12. Salimova, T. A. quality Management: textbook M; Publishing house OMGA-L,"2011 416 p 
13. Timoshenko V. A. Problems of formation and development of integrated structures in agriculture // Bulletin of Voronezh State agrarian University 2012 No. 4 p. 110

14. On approval of food security Doctrine of the Russian Federation (Electronic resource. Access from reference legal system Consultant $+"$

15. Gorelov I. N. Theoretical and practical aspects of integration APK// Actual problems of humanitarian and natural Sciences. 2009 No. 10, p. 110

16. Guajava A. S. Organizational-institutional model of management of regional agriculture based on the allocation of economic clusters. // The Bulletin of Adyghe state University n 2007, S. 220

17. Qihang T. V. the Cluster theory of economic development // theory and practice of management 2003 No. 5 s. 15

18. Lizunov V. V. et al. Clusters and cluster strategy publisher SP V. E. Skornyakova 2012280 s.

19. Treskova E. A., Semin A. N. The concept of development of rural territories: two basic approaches. // Agrarian Bulletin of the Urals No. 122012 p. 60

20. White N. In. Human capital formation in agriculture: Problems and prospects. // Bulletin of Altai state agricultural University. 2013 No. 6 s 113.

21. Ali Sasani. Investigating the Effect of Human Capital and Social Capital on Innovation Using the Fuzzy AHP Method, in: the New York Science Journal. - 2012. - № 5(11).

22. White N. In. Human capital formation in agriculture: Problems and prospects. // Bulletin of Altai state agricultural University. 2013 No. 6 s 113.

23. Ali Sasani. Investigating the Effect of Human Capital and Social Capital on Innovation Using the Fuzzy AHP Method, in: the New York Science Journal. - 2012. - № 5(11). 